\title{
ASSESSMENT OF EDUCATIONAL INTERVENTION ON KNOWLEDGE, ATTITUDE, AND PRACTICES OF RURAL COMMUNITY PHARMACISTS OF MYSURU DISTRICT TOWARD ADVERSE DRUG REACTION REPORTING
}

\author{
SRIKANTH M S ${ }^{1}$, ADEPU R ${ }^{2 *}$ \\ ${ }^{1}$ Department of Pharmacy Practice, JSS College of Pharmacy, JSS Academy of Higher Education and Research, Mysuru, Karnataka, India. ${ }^{2}$ Department \\ of Pharmacy Practice, Vikas College of Pharmaceutical Sciences, Rayanigudem, Suryapet, Telangana, India. Email: adepu63@gmail.com
}

Received: 16 October 2017, Revised and Accepted: 15 June 2018

ABSTRACT

Objective: A prospective interventional study was conducted to evaluate the impact of educational intervention on knowledge, attitude, and practices (KAP)(of rural community pharmacists toward adverse drug reaction (ADR) reporting.

Methods: A validated KAP questionnaire was administered on the enrolled community pharmacists in the study. SPSS software package version-19 was used to calculate the influence of educational intervention on KAP scores of the participants. Pre-training KAP scores were compared with the post-training KAP scores.

Results: About 49 community pharmacists have participated in the study, $95.91 \%(n=47)$ were males, and $4.08 \%$ ( $=2$ ) were females. The mean \pm SD age of the participants was $40.93 \pm 7.84$ years. The mean \pm SD score in the knowledge component was significantly increased from $4.87 \pm 2.015$ to $7.09 \pm 0.68(n=49, p<0.05)$. After the educational intervention, $77.55 \%(n=38)$ of participants could correctly define the ADRs, and $73.46 \%$ ( $=36)$ of participants were aware of the consequence of ADRs. About 57.34\% of participants disagree with the statement reporting of ADRs incurs the addtional workload with post education intervention. At the end of the study, the participants' knowledge was significantly increased and participant pharmacists felt responsible toward ADR reporting.

Conclusion: Educational interventional program have shown a tremendous change in knowledge and awareness of the respondents towards adverse drug reaction monitoring and reporting. It is well understood that there is a need for promoting the pharmacovigilance activities among community pharmacists.

Keywords: Community pharmacist, Adverse drug reactions reporting, Educational intervention.

(C) 2018 The Authors. Published by Innovare Academic Sciences Pvt Ltd. This is an open access article under the CC BY license (http://creativecommons. org/licenses/by/4. 0/) DOI: http://dx.doi.org/10.22159/ajpcr.2018.v11i10.23156

\section{INTRODUCTION}

Adverse drug reactions (ADR) are identified as one of the major contributing factors for morbidity and mortality [1]. Global studies have corroborated*ADRs as fourth to, sixth leading cause of death in hospitalized patients [2] and also have a direct influence on morbidity, ${ }^{*}$ mortality, and economic burden to the society [3]. The global epidemiological data show that $3-6 \%$ of hospital admissions are due to ADRs and the percentage of patients experiencing ADRs during hospitalization ranges from $1.5 \%$ to $35 \%$ [4]. As per a South Indianbased study, the estimated direct and indirect cost associated with the management of an ADR is about Rs.4945/- per day [5]. Findings from overseas studies reveal that the expenditure incurred in managing ADRs is ranging from few million dollars at the institutional level to billions of dollars at the national level [5]. Thus, ADRs are a significant burden to health-care systems around the world in terms of the resource consumption [1-5]. Studies have also shown that the incidence of ADRs in community settings is estimated at a rate of $57 \%$ and often goes undetected majorly due to underreporting by health-care professionals [6]. Spontaneous ADR reporting systems function worldwide to collect information on ADRs to identify early signals of drug toxicity and ultimately prevent drug-associated harm. Pharmacovigilance programs of various countries have already permitted pharmacists to report ADRs in their practice settings [6]. Despite many efforts, underreporting of ADRs still is a challenge [7]. Underreporting of ADRs by community pharmacists is due to poor understanding about the concept of ADR reporting [3-7].

Community pharmacists are easily accessible to public for any health-related issues. In recent times, pharmacists' roles were expanded from traditional dispensing to patient care services through pharmaceutical care [8]. Community pharmacists can play a vital role in the pharmacovigilance program because of their rapport with the patients [9]. Research studies have acknowledged community pharmacists' role in recognizing and reporting the ADRs to their national pharmacovigilance programs. A systematic review of ADR reporting schemes of various countries shows that quality of ADR reporting by pharmacists is on par with other health-care professionals. In India, community pharmacists' awareness and ADR reporting practice are very low. A study was conducted in Amalapuram by Sindhuja et al. to assess the knowledge, attitude, and practices (KAP) of community pharmacists toward ADR reporting. The findings suggest that community pharmacists in India do not have understanding about the ADR reporting [10]. Pilot study findings of Rakesh and Adepu in Mysuru city suggest that if pharmacists are given adequate training, they will take the responsibility of reporting ADRs [11]. Thus, this prospective interventional study was designed to assess the impact of educational intervention on community pharmacists' KAP toward ADR reporting.

\section{METHODS}

The present study was conducted involving the practicing community pharmacists of rural areas of Mysuru district, South India. Postal survey and convenient sampling methods were applied to recruit the practicing pharmacists in the study. A 20-item questionnaire was developed comprising of 8 questions assessing "knowledge" component, 6 questions assessing "attitude" component, and another 6 questions to assess "practice" component, and the questionnaire was validated with the help of clinical pharmacy professors and practicing community 
pharmacists. Both pre- and post-training questionnaire were having the same set of questions. In the questionnaire, provision was also made to capture the participants' demographic details such as name, age, sex, and educational*background and practice experience. Baseline knowledge of the participating community pharmacists was assessed by applying the questionnaire before the educational program. Impact of the educational intervention on KAP was assessed by administering the same questionnaire after 4 weeks on the study pharmacists. The Institutional Ethics Committee of JSS College of Pharmacy, Mysuru, has approved the study.

A training manual*was developed by*referring to the textbooks and published literature on ADRs and pharmacovigilance. The manual covered the information on definition, pre-disposing factors, various methods practiced to report ADRs, spontaneous reporting, global scenario of pharmacovigilance, what information should be collected from patients to report ADR, the ADR notification form, and procedure to fill the form. The content of the manual was reviewed by the senior faculty of the pharmacy practice and experts in pharmacovigilance activity.

A workshop on ADR detection, reporting, and monitoring was organized for selected rural practicing community pharmacists. During the workshop, the participants were trained about the topics covering basic introduction on ADRs, need for safety monitoring of medicines in the society, role of pharmacists in drug safety monitoring and global scenario of ADR reporting, and how to initiate and improve ADRs reporting culture among community pharmacists.

\section{Validation of the KAP questionnaire}

The KAP questionnaire was subjected for the content validity index (CVI) with the help of four-point criteria for measuring the CVI. Each question in the questionnaire was subjected for the content validity by fifteen experts in the related field. The experts were from the professors, lectures, research scholars, and pharm.D interns of the department of pharmacy practice. The researcher gave a copy of the questionnaire with the criteria for $\mathrm{CVI}$ and explained the purpose and the objective of the study individually to all experts. The experts were asked to rate each question and answer options on relevance, clarity, simplicity, and ambiguity on the four-point scale. The CVI of the scale was also measured based on the rating by the experts. The statistical analysis was performed using Microsoft Excel and the Statistical Package for the Social Science (SPSS) version 22 for windows. Cronbach's alpha was used to estimate the internal consistency of the questions in the questionnaire.

\section{RESULTS AND DISCUSSION}

The content validation of the KAP questionnaire was done and the internal consistency is presented in Table 1.

About 49 practicing pharmacists participated from six taluks of mysuru district

Among 49 community pharmacists, $95.91 \%(n=47)$ were male. The mean age of the pharmacists was $42.69 \pm 7.65$ years. The sociodemographic details of the study pharmacists are presented in Table 2.

The enrolled rural community pharmacists have completed pre- and post-training KAP questionnaire. The knowledge of community pharmacists toward ADR reporting and monitoring was assessed through 8 questions. The community pharmacists' overall pre- and post-test responses were compared based on the number of questions answered correctly, and the results were analyzed using Chi-square test in SPSS statistical software. The post educational knowledge score of participants was significantly increased from $4.87 \pm 2.01$ to $7.09 \pm 0.68$ $(n=49, p<0.001)$. Question 1 was framed to assess the knowledge of the respondents about the definition of ADR, on post-training, $77.55 \%$ $(n=38)$ of pharmacist respondents have given the correct response for this question, and a significant improvement between pre- and post-
Table 1: Internal consistency of the KAP questionnaire

\begin{tabular}{ll}
\hline Criteria & Cronbach's alpha \\
\hline Clarity & 0.782 \\
Relevancy & 0.824 \\
Simplicity & 0.814 \\
Consistency & 0.728 \\
\hline
\end{tabular}

KAP: Knowledge, attitude, and practices

Table 2: Sociodemographic details of the participant pharmacists

\begin{tabular}{ll}
\hline Characteristics & Frequency (\%) \\
\hline Gender & \\
Male & $47(95.91)$ \\
Female & $0.2(4.08)$ \\
Age in years & \\
$25-29$ & $02(4.08)$ \\
$30-34$ & $10(20.70)$ \\
$35-39$ & $09(18.36)$ \\
$40-44$ & $16(32.65)$ \\
$>45$ & $12(24.48)$ \\
Community pharmacists' qualification & \\
D. Pharm & $44(89.79)$ \\
B. Pharm & $05(10.20)$ \\
Number of years of experience as community & \\
pharmacists & \\
$<5$ & $06(12.24)$ \\
$6-10$ & $07(14.28)$ \\
$11-15$ & $15(30.61)$ \\
$>15$ & $21(42.85)$ \\
Number of prescription dispensed per day & \\
$<30$ & $21(42.85)$ \\
$30-90$ & $17(34.69)$ \\
$>90$ & $11(22.44)$ \\
Use of computer for billing & \\
Yes & $12(24.48)$ \\
No & $37(75.51)$ \\
Access to internet in pharmacy & \\
Yes & $11(22.44)$ \\
No & $38(77.55)$ \\
\hline
\end{tabular}

KAP scores was observed. Question number 2 assessed the predisposing factors for developing an ADR. The results have shown that $63.26 \%$ $(n=31)$ of the pharmacists' respondents have given the correct answer in post-KAP, whereas in pre-KAP, the response was $42.85 \%(n=21)$. The response rate is statistically significant between pre- and post-KAP. The question number 3 focused on the types of ADRs. About 52.38\% $(n=22)$ of participants gave the correct response when compared with pre-KAP assessment. Response rate for question 3 was statistically significant between pre- and post-KAP scores $(\mathrm{p}<0.05)$. Question 4 assessed about the knowledge on consequence and economic burden of ADR on the patients. The response rate for question 4 in post-KAP was found statistically significant $(\mathrm{p}<0.05)$. Questions 6 assessed about the awareness on existing national pharmacovigilance program in India. The result has shown that $83.67 \%(n=41)$ of participants were aware about existing Pharmacovigilance Program of India (PvPI). After the educational intervention, post-KAP response in this question significantly improved $(\mathrm{p}<0.05)$. Question number 7 sought information about agency that is responsible for ADR monitoring in India. Response rate for question 7 was significantly improved in postKAP test. About $63.26 \%(n=31)$ of participants were given the correct response $(\mathrm{p}<0.001)$. Question number 8 asked about which healthcare professionals are permitted to report ADRs. To this question, 16 (32.65\%) participants have correctly answered in pre-training KAP test, whereas 41 (83.67\%) participants have correctly answered in the post-training test showing a significant improvement in answering. The scores associated with knowledge component is presented in Table 3. 
While evaluating the attitudes of community pharmacists, it was observed that $42.85 \%(n=21)$ of participants have strongly agreed with the statement of "ADR reporting is the professional responsibility of pharmacists" a statistically non-significant difference was observed in pre- and post-KAP scores ( $p>0.05)$. In pre-KAP response, the majority of the participants $(n=36)$ have mentioned that reporting ADR will add additional workload to pharmacists. After the educational intervention, 51.01\% ( $\mathrm{n}=25)$ participants have expressed disagree with above-said statement which is significantly different between pre-KAP and post-KAP. At the end of the educational intervention, majority participants $87.76 \%(n=43)$ have agreed with the statement "for reporting ADRs need special knowledge" comparing to the pre-training KAP. No statistically significant difference was observed between pre-training and post-training KAP assessment $(\mathrm{p}>0.05)$. After the educational intervention, $38.77 \%(n=19)$ of the participants have expressed their disagreement with the statement "doctor will have a negative opinion on pharmacists reporting any ADR" comparing to the pre-training scores. A statistically significant difference was observed between the responses to this question in pre- and post-KAP assessment $(p<0.05)$. All the participants have agreed to the statement "If I am encouraged and trained I will take the responsibility of reporting
ADRs." The scores of Attitude are presented in Table 4.

The responses to the questions in the practice session after the education intervention were as follows. About 46.93\% $(n=23)$ participants have mentioned that they frequently check the allergy status of the patients while dispensing medications to them. About 83.67\% $(n=41)$ of participants declared that they will take the responsibility of educating the patients on safe use of medicines. About $83.67 \% \quad(n=41)$ of participants have said that they will provide counseling to their patients about potential ADRs. About $75.51 \%(n=37)$ of participants have agreed to report the ADRs to the suitable authority comparing to the pre-KAP assessment. Significant difference was observed between the responses to this question in pre- and post-intervention $(\mathrm{p}<0.05)$. The scores on practice are presented in Table 5.

This study was carried out to assess the KAP of community pharmacists toward ADR reporting. The study has also evaluated the effectiveness of the education intervention program on ADR reporting to improve the awareness* by community pharmacists in Mysuru district.

At present, in India, the minimum registrable qualification for pharmacists to practice is diploma in pharmacy (D. Pharm). Their

Table 3: Evaluation of pre- and post-training knowledge scores

\begin{tabular}{|c|c|c|c|}
\hline Questions & $\begin{array}{l}\text { Correct response before } \\
\text { training }(n=49)\end{array}$ & $\begin{array}{l}\text { Correct response after } \\
\text { training }(n=49)\end{array}$ & p value \\
\hline What is an ADR? & $14(28.57)$ & $38(77.55)$ & $<0.05$ \\
\hline $\begin{array}{l}\text { Which of the following factors predispose for developing } \\
\text { an ADR? }\end{array}$ & $21(42.85)$ & $31(63.26)$ & $<0.05$ \\
\hline Which of the following ADR classification is correct? & $10(20.40)$ & $29(59.18)$ & $<0.05$ \\
\hline Which of the following are the consequences of ADRs? & $18(36.73)$ & $36(73.46)$ & $<0.05$ \\
\hline $\begin{array}{l}\text { Which of the following organ systems of the body will be } \\
\text { affected due to an ADR? }\end{array}$ & $24(59.18)$ & $37(75.51)$ & $<0.05$ \\
\hline Are you aware of national ADR reporting system in India? & $08(16.32)$ & $41(83.67)$ & $<0.05$ \\
\hline $\begin{array}{l}\text { Which of the following agency is responsible for ADR } \\
\text { monitoring in India? }\end{array}$ & $05(10.20)$ & $31(63.26)$ & $<0.05$ \\
\hline $\begin{array}{l}\text { Which of the following health-care professionals is } \\
\text { permitted to report ADR? }\end{array}$ & $16(32.65)$ & $41(83.67)$ & $<0.05$ \\
\hline
\end{tabular}

ADR: Adverse drug reaction

Table 4: Pharmacists scores on attitude toward ADR reporting

\begin{tabular}{|c|c|c|c|c|c|c|c|c|c|}
\hline \multirow[t]{2}{*}{ Questions } & \multicolumn{2}{|c|}{ Strongly agree (\%) } & \multicolumn{2}{|l|}{ Agree (\%) } & \multicolumn{2}{|c|}{ Disagree (\%) } & \multicolumn{2}{|c|}{ Strongly disagree (\%) } & \multirow[t]{2}{*}{ p value } \\
\hline & Pre & Post & Pre & Post & Pre & Post & Pre & Post & \\
\hline $\begin{array}{l}\text { Do you think ADR } \\
\text { reporting is one of } \\
\text { the professional } \\
\text { responsibilities of the } \\
\text { pharmacists? }\end{array}$ & $21(42.85)$ & 37 (75.51) & $22(44.89)$ & 09 (18.36) & $04(8.16)$ & $03(6.12)$ & $02(4.08)$ & 00 & $>0.05$ \\
\hline $\begin{array}{l}\text { Is reporting of ADRs an } \\
\text { extra work for you }\end{array}$ & $16(32.65)$ & 08 (16.32) & $20(40.81)$ & $16(32.65)$ & $11(22.44)$ & $16(32.65)$ & $02(4.08)$ & 09 (18.36) & $<0.05$ \\
\hline $\begin{array}{l}\text { I need special } \\
\text { knowledge and skills } \\
\text { for reporting of an ADR }\end{array}$ & $23(46.93)$ & $25(51.02)$ & $16(32.65)$ & $18(36.73)$ & $08(16.32)$ & $04(8.16)$ & $02(4.08)$ & $02(4.08)$ & $>0.05$ \\
\hline $\begin{array}{l}\text { Will incentives for } \\
\text { reporting ADR be a } \\
\text { motivation for you? }\end{array}$ & $16(32.65)$ & $04(8.16)$ & $17(34.69)$ & $15(30.61)$ & $13(26.53)$ & $22(44.89)$ & $03(6.12)$ & 08 (16.32) & $<0.05$ \\
\hline $\begin{array}{l}\text { You think that doctors } \\
\text { will have a negative } \\
\text { opinion on you if you } \\
\text { report an ADR? }\end{array}$ & $13(26.53)$ & $15(30.61)$ & $26(53.06)$ & $15(30.61)$ & $08(16.32)$ & $14(28.57)$ & $02(4.08)$ & $05(10.20)$ & $<0.05$ \\
\hline $\begin{array}{l}\text { If I am encouraged } \\
\text { and trained, I will take } \\
\text { the responsibility of } \\
\text { reporting ADR }\end{array}$ & 17 (34.69) & 24 (48.97) & $25(51.02)$ & $21(42.85)$ & $05(10.20)$ & $03(6.12)$ & $02(4.08)$ & $01(2.04)$ & $>0.05$ \\
\hline
\end{tabular}


Table 5: Community pharmacists practice toward ADR reporting $(n=49)$

\begin{tabular}{|c|c|c|c|c|c|c|c|c|c|}
\hline \multirow[t]{2}{*}{ Questions } & \multicolumn{2}{|c|}{ Frequently (\%) } & \multicolumn{2}{|c|}{ Sometimes (\%) } & \multicolumn{2}{|l|}{ Rarely (\%) } & \multicolumn{2}{|l|}{ Never (\%) } & \multirow[t]{2}{*}{$p$ value } \\
\hline & Pre & Post & Pre & Post & Pre & Post & Pre & Post & \\
\hline $\begin{array}{l}\text { Before dispensing any } \\
\text { drug, how often do you } \\
\text { ask the patients about any } \\
\text { drug allergies? }\end{array}$ & $12(24.48)$ & 23 (46.93) & 23 (46.93) & $20(40.81)$ & 09 (18.36) & $06(12.24)$ & $05(10.20)$ & 00 & $>0.05$ \\
\hline $\begin{array}{l}\text { How often you talk about } \\
\text { safe use of medicines? }\end{array}$ & 19 (38.77) & 13 (26.53) & $21(42.85)$ & $28(57.14)$ & 07 (14.28) & 08 (16.32) & $02(4.08)$ & 00 & $>0.05$ \\
\hline $\begin{array}{l}\text { How often you counseled } \\
\text { about adverse effects? }\end{array}$ & 09 (18.36) & 15 (30.61) & 27 (55.10) & $26(53.06)$ & $08(57.14)$ & 07 (14.28) & $05(10.20)$ & $01(2.04)$ & $>0.05$ \\
\hline $\begin{array}{l}\text { How often do you report } \\
\text { the suspected ADR to a } \\
\text { suitable authority }\end{array}$ & $05(10.20)$ & $12(24.48)$ & 15 (30.61) & $21(42.85)$ & $14(28.57)$ & $12(24.48)$ & $15(30.61)$ & $04(8.16)$ & $<0.05$ \\
\hline $\begin{array}{l}\text { How often you reported } \\
\text { the ADR to Monitoring } \\
\text { Centre }\end{array}$ & $02(4.08)$ & $12(24.48)$ & 08 (16.32) & $25(51.02)$ & $06(12.24)$ & 08 (16.32) & $33(67.34)$ & $04(8.16)$ & $<0.05$ \\
\hline $\begin{array}{l}\text { How often you have } \\
\text { collected the necessary } \\
\text { information to improve the } \\
\text { quality of reporting }\end{array}$ & 00 & 07 (14.28) & 08 (16.32) & $22(44.89)$ & $11(22.44)$ & $13(26.53)$ & $30(61.22)$ & 07 (14.28) & $>0.05$ \\
\hline
\end{tabular}

ADR: Adverse drug reaction

awareness toward ADRs and pharmacovigilance activity are very minimal. Reasons for this situation are due to lack of instruction about ADRs and role of the pharmacists in reporting ADRs at diploma in pharmacy course, trader attitude of the practicing pharmacists, and nonavailability of practice guidelines for the pharmacists in India.

Community pharmacy is an important point of contact for the patients where they can procure their medicines and share their problems regarding drug therapy if any with the pharmacist.

As per the World Health Organization definition, pharmacovigilance is detection, reporting, assessment, and prevention of adverse drug effects in humans. Community pharmacists are well trained to offer the pharmaceutical care to patients for safe use of medication and help patients to receive the best therapeutic benefits. As part of pharmaceutical care process, patients are motivated for potential ADRs. Worldwide, pharmacovigilance activity is becoming a priority for all health-care professionals as the drug safety is becoming paramount. Majority countries have developed their own pharmacovigilance programs and encouraging all their health-care professionals to report ADRs. In few countries, community pharmacists are playing the lead role in ADR reporting. In the Netherlands, more than $40 \%{ }^{*}$ of ADR reports received by Lareb are from the community pharmacists indicating their dedication toward monitoring and reporting ADRs. Few studies have also assessed the quality of reporting by community pharmacists compared with that of reports received from doctors. The findings suggest that, the quality of pharmacists reporting is on par with reports received from clinicians [12].

Before the educational intervention, the majority of the participant pharmacists were not aware of existing pharmacovigilance program in India, and they did not know how to report and where to report ADRs. The study findings have demonstrated that the community pharmacists possess a positive attitude toward ADR reporting, although the majority of them never reported any ADRs. In a study conducted by Cheema et al. in London observed in their study "Community Pharmacist-Led New Medicines Service for patients with long-term medical condition - A cross-sectional study has revealed that ADR reporting has identified new service by community pharmacists to be offered to the patients voluntarily to identify potential ADRs that lead to increased morbidity in patients with chronic diseases not only improves patients health but also the reputation to the pharmacist [13] that similar findings were also observed in the studies conducted at United Arab Emirates and Malaysia with respect to the positive attitude of the community pharmacists in reporting ADRs in the community*pharmacy settings $[12,14,15]$.
Knowledge and skills are essential in providing meaningful and useful professional service. It is always important for all healthcare*professionals to have the necessary*knowledge and attitude to do any professional service. Despite many efforts by the national pharmacovigilance program action committees, ADR reporting in many countries is not picking up*commendably. One of the major reasons for underreporting was found as "lack of knowledge and poor attitude" toward ADR reporting among health-care professionals [14].

Thus, the current study was focused to assess pre and post educational intervention on "KAP" of participants toward ADR reporting. The findings suggest that the knowledge component score of the participants has increased from pre-training test score of $4.87 \pm 2.01$ to post-test score of $7.09 \pm 0.68$, which is a significant improvement $(\mathrm{p}<0.001)$ suggesting the influential role of training on exit-level knowledge of the participants. Findings of various studies regarding assessment of KAP of pharmacists toward ADR reporting suggest that pharmacists have inadequate knowledge regarding ADRs, predisposing factors and reporting of ADRs [15].

The findings of the study also recommended that if the pharmacists are sensitized and trained, they will take the responsibility of reporting ADRs. This finding was consistent with Jose et al. [16] study where it was opined that educational interventions have to be continued to enhance their awareness on how to report ADR and motivate the pharmacists' toward active participation in the ADR reporting program.

In this study, it was observed that inadequate awareness about the PvPI has contributed toward the underreporting of ADRs. Further, the majority of the participants in this study (69.73\%) do not possess computer and internet facility at their practicing sites as their pharmacies are in rural areas. This may be another contributing factor toward underreporting.

In a pilot study conducted in Oman by Jimmy Jose et al., the findings suggest that though majority respondent pharmacists have basic knowledge about ADR reporting but require continuous educational support to update*their knowledge and reporting behavior [16]. In another study conducted by Elkalmi et al. in Malaysia, the educational intervention has significantly improved the knowledge of the respondent community pharmacists $(\mathrm{p}<0.001)$ compared to the pre educational intervention suggesting the importance of continuous education [12]. However, according to a study conducted by Ravinanadan et al. [17] revealed that the community pharmacists were 
having low knowledge and poor attitude toward ADR reporting. On similar notes, a study conducted by Elkalmi et al. in Malaysia assessing the northern Malaysian states community pharmacists' attitudes, perceptions and barriers toward ADR reporting, the findings suggest that the majority of respondent community pharmacists were unaware about ADR reporting system, and only a few pharmacists have reported ADRs to national pharmacovigilance*system [12].

These findings emphasize the need for regular motivation to the practicing community pharmacists toward ADR reporting. Motivational strategies*include continuous educational support to the community*pharmacists, wide publicity*about the pharmacovigilance activities among the pharmacists through newsletters, sending thank you notes to the pharmacists whenever a report is sent to the pharmacovigilance program and publishing the photo of the pharmacists in news letter, etc.

In our study, the post education intervention responses show that majority pharmacists have considered ADR reporting as one of their professional responsibility apart from the drug dispensing. This attitude in pharmacists was changed due to educational intervention and briefing them about pharmacists role in national pharmacovigilance program. The practice licensing authorities such as state pharmacy councils or pharmaceutical associations or boards of pharmacies should take the lead in this direction to motivate the practicing pharmacists toward the medication safety assessment activity. To achieve this, pharmacy council of India has come out with Pharmacy Practice Regulations in 2015. All state pharmacy councils should implement these practice regulations, upgrade pharmacist's knowledge and skills and motivate them toward the patient care activities, including pharmacovigilance activity.

\section{CONCLUSION}

The study findings concluded that pharmacists have inadequate knowledge about ADRs, the importance of spontaneous ADR reporting system, and PvPI activities. Educational intervention has significantly improved KAP of the community pharmacists toward ADR reporting. However, there is a strong need to implement practice regulations and regulatory interventions periodically to improve the understanding*of safety reporting among the practicing community pharmacists.

\section{ACKNOWLEDGMENTS}

We express sincere thanks to University Grant Commission (UGC), Government of India for funding this project, JSS Academy of Higher Education \& Research for providing all facilities and encouragement, The Principal,Head and other colleagues, Department of Pharmacy Practice, JSS College of Pharmacy, Mysuru for valuable support in completing the present work. Authors also express their sincere gratitude to all the community pharmacists who have participated in this study.

\section{AUTHOR'S CONTRIBUTION}

Both authors have contributed equally for the research work in designing the research project, developing the training module and necessary assessment questionnaires, and also in enrolling the practicing pharmacists for the proposed work.

\section{CONFLICTS OF INTEREST}

Authors have declared that there are no conflicts of interest.

\section{REFERENCES}

1. Kalaiselvan V, Prasad T, Bisht A, Singh S, Singh GN. Adverse drug reactions reporting culture in pharmacovigilance programme of india. Indian J Med Res 2014;140:563-4.

2. Kvasz M, Allen IE, Gordon MJ, Ro EY, Estok R, Olkin I, et al. Adverse drug reactions in hospitalized patients: A critique of a meta-analysis. Med Gen Med 2000;2:E3.

3. McDonnell PJ, Jacobs MR. Hospital admissions resulting from preventable adverse drug reactions. Ann Pharmacother 2002;36:1331-6.

4. Adhikarya J, Bhandare B, Adarsh E. A study to assess knowledge, attitude, and practice of adverse drug reaction reporting among physicians in a tertiary care hospital. J Evol Med Dent Sci 2013;2:1027-34

5. Rajakannan T, Mallayaswamy S, and Guddattu V. Cost of adverse drug reactions in a south Indian tertiary care teaching hospital. J Clin Pharmacol 2012;52:559-65.

6. Mandavi, D'Cruz S, Sachdev A, Tiwari P. Adverse drug reactions and their risk factors among Indian ambulatory elderly patients. Indian J Med Res 2012;136:404-10

7. Farcas A, Bojita M. Adverse drug reactions in clinical practice: A causality assessment of a case of drug-induced pancreatitis. J Gastrointestin Liver Dis 2009;18:353-8.

8. Adepu R, Nagavi BG. General practitioners perceptions about the extended roles of community pharmacists in the state of Karnataka: A study. Indian J Pharm Sci 2006;68:36-40.

9. van Grootheest K, Olsson S, Couper M, de Jong-van den Berg L. Pharmacists' role in reporting adverse drug reactions in an international perspective. Pharmacoepidemiol Drug Saf 2004;13:457-64.

10. Sindhuja CH, Begum SK, Suryateja P and Sudha P. Knowledge, attitude and behaviour of community pharmacists towards ADR reporting. Int $\mathrm{J}$ Pharm Sci 2015;7:258-61

11. Rakesh CP, Adepu R. Design and implementation of adverse drug reaction reporting system in community pharmacies. Indian J Pharm Pract 2009:2:32-7.

12. Elkalmi RM, Hassali MA, Ibrahim MI, Jamshed SQ, Al-Lela OQ. Community pharmacists' attitudes, perceptions, and barriers toward adverse drug reaction reporting in Malaysia: A quantitative insight. J Patient Saf 2014;10:81-7.

13. Cheema E, Sutcliff P, Singer DR. Community pharmacist-led new medicine service for patients with a long term medical condition: A cross-sectional study. Int J Pharm Sci 2017;9:129-33.

14. Mulatu WN, Worku A. Assessment of knowledge, attitude and practice of health professionals towards adverse drug reaction reporting and factors associated with reporting. J Pharm 2014;2:1-7.

15. Qassim S, Metwaly Z, Shamsain, M. Reporting adverse drug reactions: Evaluation of knowledge, attitude and practice among community pharmacists in UAE. IOSR J Pharm 2014;4:2319-4219.

16. Jose J, Jimmy B, Al-Ghailani AS, Al Majali MA. A cross sectional pilot study on assessing the knowledge, attitude and behavior of community pharmacists to adverse drug reaction related aspects in the sultanate of Oman. Saudi Pharm J 2014;22:163-9.

17. Ravinanadan AP, Achutha V, Ramani VK, Uttangi S, Kumar SL. Study of knowledge, attitude, and practice of pharmacists towards adverse drug reaction reporting in Davangere City. Asian J Pharm Clin Res 2015;8:262-5. 